\title{
EVALUATION OF OVERALL PERFORMANCE OF FACULTY MEMBERS BY USING SELF-ASSESSMENT METHOD
}

\author{
Santosh Shah, ${ }^{1}$ Anand Kumar, ${ }^{1}$ Nabaraj Pokharel ${ }^{2}$
}

\begin{abstract}
INTRODUCTION

The quality of teaching learning process at medical college depends mainly on infrastructure that includes competent personnel, optimal teaching space and equipment in accordance with existing standards and norms. Faculty hence remains the cornerstone of overall academic performance of institution. Faculty evaluation and faculty development training strengthens further academic excellence. Self-assessment of their own teaching performance by faculties is highly efficient for further academic improvement and enhancement.
\end{abstract}

\section{MATERIAL AND METHODS}

A Cross sectional, prospective study was conducted among 134 faculty members of various departments at Universal Medical College and Teaching Hospital (UCMS), Bhairahawa in month of June 2019. Faculty from clinical, basic, dental and nursing sciences were included in this study. Assessment were done with standard questionnaire with 8 different variables was using the Likert scale. A semi-structured self-administered questionnaire was used for collection of data. All the respondents provided opinion regarding level of skill, level of dependability, skill in patient relation, commitment to organization, efficiency to organize work, overall quality deliver to workplace, productivity, level of team work by a 5 points rating scale. They were provided with questionnaire and they were asked to fill form with using self-assessment methods. Data were analyzed using Microsoft excel and represented as frequency and proportion.

\section{RESULTS}

A total of 134 lecturers from various faculties participated in this study. Majority of participants (40\%) are from basic sciences. In this study majority of faculties assessed themselves as competent in regards of skill (12\%), clinical faculties find themselves efficient in regard of organization of work schedule. Sixteen participants found themselves dependent on others in their work. When they were asked to rate their patient related skills, six members from basic sciences were unsatisfied while all the clinicians find that they meet the job requirement and expectations. All participants believe in team work and majority of them were committed towards the organization.

\section{CONCLUSION}

The self-assessment by faculty themselves is equally effective to plan faculty development programs for further improvement and enhancement.

KEY WORDS Faculty, Evaluation, Self-assessment.

1. Department of Surgery, Universal College of Medical Sciences, Bhairahawa, Nepal

2. Principal Office, Universal College of Medical Sciences, Bhairahawa, Nepal

DOI: http//doi.org/10.3126/jucms.v8i02.34311

\author{
For Correspondence \\ Dr. Santosh Shah \\ Department of General Surgery (CTVS) \\ Universal College of Medical Sciences \\ Bhairahawa, Nepal \\ Email: shahsant366@gmail.com
}




\section{INTRODUCTION}

The education system in every country, as a dynamic and targeted institution has qualitative and quantitative dimensions and a balanced growth of these dimensions is one of the main objectives of this system that must always be taken into consideration by the planners. ${ }^{1}$ Continuous improvement of the quality of education requires continuous evaluation of its functions. This evaluation can be carried out on the basis of each of its elements such as input, output, processes, and outcome.

Evaluation is one of the most effective things for quality assurance and continuous quality improvement process in the educational system., ${ }^{3,4}$ The basic aim is to improve effective activities and to weaken or eliminate non-effective and undesirable ones. ${ }^{4}$ The obtained information from evaluation can be used to improve and develop training programs, teaching methods, planning, etc. ${ }^{5}$ Chickering believes that evaluation is the basis of perfection and development and regards it in many different aspects, such as personality development, morality, intellectuality, motivation, and knowledge.

Faculties are one of the main pillars of Medical Institutions and their function plays a fundamental role in the overall efficiency of University educational system. Therefore, it is necessary that the quality of their performance be continuously and systematically examined and the results presented to them, punctually. Numerous studies have shown that the feedback of these results will enable faculties to identify their strengths and weaknesses in order to improve the former and overcome the latter. This process will improve the quality of education and sevice. ${ }^{7,8}$ It further adds to dynamicity in the system.

The aim of faculties' evaluation is to determine their success rate in achieving decisive educational goals. To do this, an appropriate means (valid and reliable) in the field of educational work must be provided for data collection at first. Then the gathered data must be compared to standard criteria. Finally, judging about the success rate of faculties in achieving the goals must be done. ${ }^{9}$

Regarding facts, including high-speed development of science, the increasing volume of human knowledge, changes in teaching and learning methods, and lifelong self-directed learning, self-assessment is necessary and unavoidable in an academic community, especially for faculties, as future architects of every country. Obviously, the basic requirement of this capability is self-assessment. In this way, faculties can recognize their shortcomings, attitude, and performance; therefore, they can develop their qualifications. ${ }^{3}$

\section{MATERIALS AND METHODS}

A cross sectional study was conducted among 134 Lecturers of various departments at Universal College of Medical Sciences and Teaching Hospital (UCMS), Bhairahawa, Nepal during the month of June 2019. Faculty from clinical, basic, dental and nursing sciences were included in this study. Assessment were done with standard questionnaire with 8 different variables was using the Likert scale. A semi-structured selfadministered questionnaire was used for collection of data. All the respondents provided opinion regarding level of skill, level of dependability, skill in patient relation, commitment to organization, efficiency to organize work, overall quality deliver to workplace, productivity, level of team work by a 5 points rating scale. They were provided with questionnaire and they were asked to fill form with using self-assessment methods. Data were analyzed using Microsoft excel and represented as frequency and porportion.

\section{RESULTS}

A total of 134 Lecturers from various departments participated in this study. Majority of participants are from basic sciences (40\%). In this study faculties assessed themselves as competent in regards of skill $(12 \%)$, clinical faculties find themselves efficient in regard of organization of work schedule. Sixteen participants found themselves dependent on others in their work. When they were asked to rate their patient related skills, six members from basic sciences were unsatisfied while all the clinicians find that they meet the job requirement and expectations. All participants believe in team work and majority of them were committed towards the organization(Fig.1)

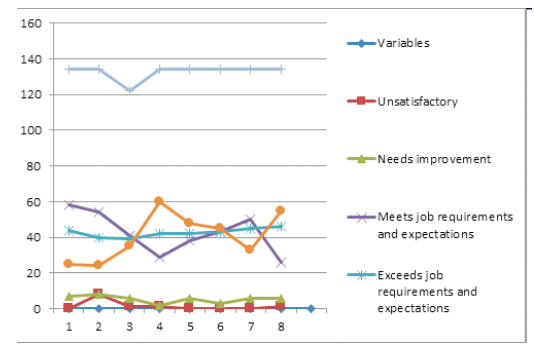

Figure 1. Five point rating scale

\section{DISCUSSION}

The purpose of this study was to survey and compare the results of faculties evaluation based on self-assessment. Aultman believes that teacher evaluation by students can be a valuable feedback to improve the quality of their education and provide a good chance to lead to the promotion of learning. ${ }^{10}$ 
In a research conducted in this regard in Jahrom Medical School, it was found that $70.9 \%$ of faculties generally agreed with teacher evaluation by students and $65.7 \%$ of them believed that awareness of the aims of evaluation increased their satisfaction from the performed evaluation. ${ }^{9}$

Another group of investigators disagree with the assessment of faculties by students and believe that students' judgments are subjective and thus are not sufficiently valid. ${ }^{11}$ According to this group of researchers students lack sufficient information about faculties. ${ }^{12-14}$

Greenwood is opposed to evaluation of faculties by learners and believes that perceptions and judgments of people are affected by general personality traits and by environmental characteristics; hence, these factors can affect students and they apply them in their faculties evaluation. ${ }^{15}$

Finally, a third group of researchers have postulated that faculties evaluation by students is important and necessary, but they believe that these judgments and decisions can only be used as one of multiple evaluation sources. According to this group, since evaluation of faculty members is a complex one, and means employed and measurement modalities are not of high credit, the obtained information cannot be accurate and without bias. Therefore, they have suggested that for the final judgment, a combination of assessment information must be used and cited. ${ }^{16}$ According to Jacobs, faculties evaluation by students should not be the only source of gathering information about their decision, but other methods like selfassessment must be applied. ${ }^{5}$ Moreover, the difference between self-assessment scores compared and scores of faculties by students is statistically significant $(p=0.02)$. This means that the scores given by the faculties themselves were more than the ones given to them by students. In this study, all the participants were assessed through self-assessment procedure and they believe in team work and majority of them were committed towards the organization.

\section{CONCLUSION}

In this study, faculty members were assessed through selfassessment procedures, cited in this study, and a significant difference among them is observed as previously reported in other studies. The self-assessment by faculty themselves is equally effective to plan faculty development programs for further improvement and enhancement.

\section{ACKNOWLEDGEMENT}

We would like to acknowledge all the faculty members of Universal College of Medical Sciences, Bhairahawa, Nepal, for their active participation in self-assessment procedure.

\section{REFERENCES}

1. Segers M, Dochy F. Quality assurance in higher education: Theoretical consideration and empirical evidence. Stud Educ Eval. 1996;22:115-37

2. Hassanzadeh Taheri MM, Riyasi HR, Miri MR, Davari MH, Hajiabadi MR. Survey of observing educational rules and regulations by educational staff in different faculties of Birjand University of Medical Sciences. Journal of Birjand University of Medical Sciences. 2009;16:58-65.

3. Shumway JM, Harden RM Association for Medical Education in Europe. AMEE Guide No. 25: The assessment of learning outcomes for the competent and reflective physician. Med Teach. 2003;25:569-84.

4. Jafari HM, Vahidshahi K, Kosaryan M, Mahmoodi M Comparison between the results of academic staff selfassessment and those made by the students, Faculty of Medicine, Mazandaran University of Medical Sciences, 2006. J Mazandaran Univ Med Sci. 2007; 17:67-74.

5. Jacobs LC. University faculty and students' opinions of student rating. Bloomington, In:Bureau of evalutive studies and testing (ERIC Document Reproduction Service No.ED 291).1987;291.

6. Chickering AW. San Francisco: Jossey Bass; 1981. Associates (EDS). The American Modern College; pp. 373-83.

7. Afshar M, Hasanzadeh Taheri MM, Ryasi HR, Naseri M. Evaluation of faculty members by students with different educational development. Journal of Birjand University of Medical Sciences. 2010;17:118-26

8. Sarchami R, Salmanzade H. The view of faculties of Iran University of Medical Sciences about effect of evaluation on teaching effectiveness. Journal of Ghazvin University of Medical Sciences. 2005;34:67-71.

9. Amini M, Honardar M. The view of faculties and medical students about evaluation of faculty teaching experiences. Koomesh Journal of Semnan University of Medical Sciences. 2008;3:171-8

10. Aultman LP. An unexpected benefit of formative student evaluations. Coll Teach. 2006;54:251-8.

11. Shakournia A, Motlagh MA, Malayeri A, Jahanmardi A, Kamili Sani H. The view of Jondishapour Medical University students about faculty evaluation. Iranian J Educ Res. 2005;5:109-17.

12. Ley R. Tenure and student evaluations of teaching. Coll Stud J. 1981;15:147-50.

13. Prisco D. Student evaluation of instruction in higher learning. Coll Student J. 1979;13:290-3.

14. Rotem A, Glassman N. On the effectiveness of students' evaluative feedback to University instructors. Rev Educ Res. $1979 ; 49: 497-510$

15. Greenwood GE, Bridges CM, Ware WB, McLean JE. Student evaluation of college teaching behaviors instrument: A factor analysis. J Higher Educ. 1973;44:596-604.

16. Morrison J. ABC of learning and teaching in medicine: Evaluation. BMJ. 2003;326:385-7. 